\title{
Review of heavy metal pollution by mining
}

\author{
Qin $\mathrm{Yi}^{1, *}$, and Huang Cheng ${ }^{2}$ \\ ${ }^{1}$ National Research Center for Geoanalysis, Beijing 100037, China \\ ${ }^{2}$ China Aerospace Environmental Development Co.,Ltd, Beijing 100071, China
}

\begin{abstract}
Heavy metal pollution in soil is an unavoidable problem along with mining activities. This paper has reviewed the current research status of heavy metal pollution in mine soils in five aspects. They are evaluation methods of heavy metal pollution, migration activities of heavy metals in soil, migration mechanism, spatial distribution model and development trend of mine pollution research.
\end{abstract}

\section{Assessment of heavy metal pollution}

At present, in the evaluation of heavy metal pollution in mining areas, the commonly used evaluation methods includes total amount method, chemical speciation analysis method and biological indicator method.

The total amount method is the earliest adopted method. It judges the impact of tailings and slag on the ecological environment of the mining area based on the content of heavy metals in the pollution of the mining area. The higher heavy metals content exist in the samples, the greater the potential environmental impact of tailings and slag will be.

However, recent studies have shown that the content of heavy metals is not the decisive factor to determine the degree of heavy metal pollution to the environment. The content of heavy metals and their physical and chemical forms determine the pollution status and potential bioavailability of heavy metals. Therefore, chemical speciation analysis has become the dominant method for heavy metal pollution assessment. Chemical speciation analysis uses one or more chemical reagents to extract heavy metals from samples. According to the extraction degree of heavy metals, heavy metals in samples are artificially divided into different forms. According to extraction agents and steps, chemical morphological analysis can be divided into two categories, namely continuous extraction method and single extraction method.

As perceived as one of the most promising methods, plant indicator method is rapidly developing. In the polluted soil adjacent to mining area, some plants are found as biological indicators to directly determine the degree of soil pollution according to the amount of heavy metals absorbed by them. However, this method is still in the process of developing with some problems remains to be solved, such as the selection of indicative plants, the scope of application and which part of the tissue roots, stems, leaves, fruits and which growing stage plants can be used as indicators.

\section{Study on migration of heavy metals in soil}

Primary mineral composition and supergene environment are two principal factors affect the migration of heavy metals in mines. The primary mineral composition is mainly related to the geological characteristics of the deposit, ore type and processing technology. Tailings from different mines have different types and compositions. Water-gas-mineral reaction and its reaction products in tailings under supergene environment are also quite different. At present, the research on the release and migration of heavy metals in tailings is generally carried out through the study of tailings mineralogy and leaching simulation experiments.

Michele [1] comparatively studied the mineral and geochemical characteristics of high sulfide carbonaterich tailings and low sulfide carbonate-free tailings. It is found that the pore water $\mathrm{pH}$ of sulfide-rich carbonate tailings is 7 to 8.3 , and no secondary minerals, heavy metals and acid water are found, which indicates the sulfides are almost not oxidized. In low sulphide carbonate-free tailings, high concentration of heavy metals, a large number of secondary minerals and acid drainage are found, which means strong oxidation of sulphides happens and thereby cause heavy metal pollution. The fact reveals that whether acid water is discharged from tailings or whether heavy metals are released depends not only on the content of carbonate minerals, but also on the content of sulfides. Sulfide oxidation is the main mechanism of acid production and heavy metal release. Moreover, acid production is mainly related to pyrite and pyrrhotite oxidation. The release of heavy metals comes from different minerals, zinc and cadmium are related to sphalerite, copper is related to chalcopyrite, $\mathrm{Co}$ and $\mathrm{Ni}$ are related to pyrite and pyrrhotite, and lead is converted into alum when galena is oxidized. The concentration of lead in leachate is very low. Minerals with acid reaction activity

\footnotetext{
* Corresponding author: yiyiustb@163.com
} 
especially carbonate minerals, react with acid produced by sulfide oxidation to neutralize the ion hydrolysis and precipitation produced by sulfide oxidation.

In order to trace the dynamic geochemical process of mine tailings, Alakangas et al selected an abandoned copper mine in Sweden to carry out a key study [2]. The study investigates chemical and mineral characteristics of minerals in groundwater, surface water and tailings in different periods. It was found that oxidation of sulfide minerals in tailings ponds resulted in clear chemical zoning. The study of oxidized and unoxidized tailings shows that the elements as $\mathrm{La}, \mathrm{S}, \mathrm{Y}, \mathrm{V}, \mathrm{Ni}, \mathrm{Li}, \mathrm{Co}, \mathrm{Zn}$, $\mathrm{Cu}$ and $\mathrm{Cd}$ in oxidized sulfides are obviously depleted, while elements as $\mathrm{Al}, \mathrm{Mg}$ and $\mathrm{K}$ in silicate rock-forming minerals have no obvious changes. In addition, the metals released by oxidation and weathering of sulfide minerals are basically trapped in tailings ponds, and only $5 \%-10 \%$ of the metals are released to surface water. $\mathrm{Zn}$, $\mathrm{Cd}, \mathrm{Co}$ and Ni may be secondary bound to the tailings due to the adsorption of a large number of unweathered tailings, while $\mathrm{Cu}$ forms an obvious enrichment zone just below the front of the oxidation zone. When the oxidation front is close to the groundwater diving surface, the oxidation of sulfides almost stops. The enriched $\mathrm{Cu}$ may be partially dissolved and migrated with the movement of groundwater. The acidic water leaching from the oxidation zone also causes the adsorbed $\mathrm{Zn}, \mathrm{Cr}$, $\mathrm{Co}$ and $\mathrm{Ni}$ to dissolve again and be transferred.

Ghassen [3] studied the occurrence and migration characteristics of heavy metals in soil by element extraction method. The extraction quantity of heavy metals was analyzed by changing extraction conditions $\left(\mathrm{CaCl}_{2}\right.$, diethylenetriamine pentaacetic acid, low molecular organic acid, etc.). Combining with the analysis results of soil samples, the migration characteristics of heavy metals under certain conditions were deduced, and it was found that heavy metals were determined in soil. The most important factor of migration characteristics is the mineral composition of soil samples, followed by extraction conditions. Physicochemical characteristics of soil itself $(\mathrm{pH}$, total carbonate content, cation exchange capacity, etc.) are not determinants. By comparing the contents of heavy metals in different phases under different conditions, it is concluded that a variety of environmental factors simultaneously affect the migration of heavy metals between water and sediments [4]. Wang Yixian et al. [5] carried out leaching experiments and static immersion dissolution experiments using self-designed large-caliber leaching column. The results show that the existing state of elements has a great influence on the leaching degree. Preferential flow can bring out a large number of heavy metals, so the formation of preferential flow should be prevented as far as possible.

\section{The transfer mechanism theory}

The oxidizable component of tailings is sulfide, which releases a certain amount of $\mathrm{H}^{+}, \mathrm{Fe}^{\mathrm{x}+}, \mathrm{SO}_{4}{ }^{2-}$ and other metal ions into the pore water of tailings by oxidation. At the same time, the released acidic solution accelerates the oxidation and dissolution of sulfides and other rockforming minerals, so that more elements are released and migrated from tailings. In fact, not all components of minerals take part in oxidation. Many complex factors, such as humidity, structure and particle size of tailings, deposit depth, mineral morphology, $\mathrm{O}_{2}, \mathrm{pH}$ and organic matter content, affect the oxidation of tailings. Heavy metal migration is also controlled by a series of complex precipitation-hydrolysis, ion exchange, neutralization and adsorption/desorption reactions.

Considering complexity of heavy metal migration mechanism in mines, most of the reported migration models are based on a few important factors. For example, the research group of Central South University, based on the theory of underground seepage, designed parameters according to the theory of hydrodynamic dispersion of porous media in soil, simulated and established a model of heavy metals migration from tailings to specific soil with acid mine wastewater under specific mining conditions. The concentration change and dissolution reaction rate of heavy metal ions during the migration process were described by differential equations.

The adsorption of heavy metals in soil was listed as the main factor, and the adsorption kinetics model was established. For example, Zhang Fengjie [6] used static batch experiments to study the adsorption properties of lead, zinc and copper in soils. The results showed that the Freundlich equation could better describe the isothermal adsorption process of three metals in soils. Li Zirui [7] et al. analyzed the migration process of lead in the soil of Dechuan Copper Mining Area in Jiangxi Province by soil column leaching experiment. It was found that lead did not penetrate completely during the experimental period of soil column. There were many competitive adsorptions in soil column, and the adsorption of lead in soil basically reached dynamic equilibrium.

\section{Research on spatial distribution model}

Most studies on the spatial distribution of mine pollutants tend to analyze the variation characteristics of pollution index along the line. For example, Guo Wei and others [8] investigated the pollution status of heavy metals in the soils of Baotou tailings reservoir area and Baiyun Obo iron mine mining area in Inner Mongolia. Taking the mining area as the center, they drew lines in the northeast, southeast, southwest and northwest directions of the area, studied the linear distribution characteristics of heavy metals pollution, and explained the promotion effect of the dominant wind direction and traffic along the line on pollutant diffusion. This kind of research method neglects a large number of influencing factors, and the establishment of conclusions depends on the descriptive relationship between the analysis results and influencing factors. This method cannot establish a generalized model because of lacking quantitative identification. 
The application of mathematical tools solves this problem. Statistical analysis improves the scientificity of the results. Principal Component Analysis, Cluster Analysis, Factor Analysis, Fuzzy Discrimination, SelfOrganizing Map and other methods [9, 10] have advantages in the analysis of multi-dimensional factors and can be used to analyze the contribution of pollution sources. Among them, the absolute principal component score-multiple linear regression (APCS-MLR) is one of the most classical receptor models for water pollution source analysis. However, such analysis based on the physical characteristics of data often lacks management significance. In view of this, Wu Jiaping [11] of Zhejiang University will combine the classical APCSMLR receptor model of source analysis with the management framework of river functional zoning to analyze the pollutant sources of different water functional zones in Qiantang River Basin, with a view to providing reference for integrated watershed management. The study considers the influence of geological area, but neglects the influence of many geological factors (topography, altitude, wind direction, rainfall runoff infiltration, etc.).

The application of Geographic Information System (Gis) effectively overcomes the above shortcomings. Thanks to its powerful spatial analysis ability and visualization of results, it has been widely used in many fields such as geological environment survey in recent years $[12,13]$. The Institute of Geographic Sciences and Resources, Chinese Academy of Sciences, has many applications in China. Spatial analysis method is applied to mine pollution investigation. First, the digital terrain model of the target area is established, and sampling points are laid out with geographic information. The distribution characteristics of pollutants and sea waves, wind direction, the relationship between horizontal and vertical distance and slope are discussed by means of spatial autocorrelation was analyzed [14].

$\mathrm{Li}$ [13] showed the blocking effect of plants on the migration of low concentration heavy metals by Gis's mapping function. Multidimensional spatial analysis can comprehensively explain the spatial distribution characteristics of pollutants and their influencing factors.

\section{Development Trends of Mine Pollution Research}

Many studies suggest integrating some variables, such as biological prediction variables, physical soil parameters, and chemical measurements, to assess the type, extent, distribution and impact of heavy metal pollution. Among the physical parameters, the measurement of soil magnetic susceptibility can quickly and efficiently distinguish heavy metal pollution. Many controlling factors of spatial change make the measurement of soil magnetic susceptibility reliable, effective and sensitive. This method is fast and non-destructive, which can complement the shortcomings of traditional chemical analysis and allow the measurement in a short time and wide area. Mariagrazia D'Emilio et al. [15] provide integrated high-resolution multispectral data and prediction of heavy metal distribution in soils with high anthropogenic disturbance based on surface technology, i.e. soil magnetic susceptibility analysis and chemical analysis methods. The results show that the abnormal distribution of NDVI values has a significant negative correlation with soil magnetic susceptibility values, which provides the possibility to reduce the time and cost of prediction. Space satellite detection and field survey can be used to distinguish high-risk areas of pollution and optimize the number of sampling points for chemical analysis. The method of data integration can also help to identify high-risk areas of vegetation destruction and help to achieve the effect of prevention and protection of vegetation. When studying the Anle River Plain [16], the research team of Wuhan University in China integrated the pollution distribution of $\mathrm{Cu}$ and $\mathrm{Pb}, \mathrm{DEM}$, remote sensing images, land use data mapping of $\mathrm{Cu}$ and $\mathrm{PB}$, identified the sources and transmission routes of heavy metal pollution, and obtained the highrisk areas of pollution. As the most important factor, topography controls the spatial distribution of $\mathrm{Cu}$ and $\mathrm{PB}$. The runoff from rainfall is the main source of heavy metal pollution. Therefore, combined with multi-source data, accurate mapping and visual display of heavy metal pollution can better understand the situation of pollution.

As far as the development trend of soil quantitative technology is concerned, soil heavy metal pollution monitoring gradually develops to higher precision Micro-exploration technology and time-saving mesoand macro-monitoring technology; remote sensing, GPS and other scientific means can only estimate the content of heavy metals in soil in a large area and quickly, but not the accurate value, so the further precision of monitoring is studied by scholars. Hotspots: Remote sensing technology can be used to locate heavy metals in soil or to analyze the dynamic changes of remote sensing images in different time phases.

\section{Conclusions}

Heavy metal pollution in mine soils is highly migratory. Especially the pollution caused by minerals with acid reaction activity, the migration of heavy metals promotes the expansion of the pollution scope. Current research on heavy metal pollution in soil has the following limitations. There is no unified and standardized evaluation method for heavy metal pollution. The technical means for effective and real-time monitoring of pollution status are not mature and perfect enough. The research on migration mechanism and migration model is mostly limited to explaining case phenomena. Multidisciplinary cross-application is conducive to promoting the development of this field from the theoretical and technical levels, and is also an inevitable requirement to solve existing problems.

\section{Acknowledgement}

Thanks to the financial support from China Geological Survey Research Fund (CGS Research Fund: JYYWF20182602). 


\section{References}

1. M.P. Boulet, A.C.L. Larocque, Environ. Geol. 33, 130 (1998)

2. L. Alakangas, B. Öhlander, A. Lundberg, Sci. Total Environ. 408, 1386 (2010)

3. G. Daldoul, R. Souissi, F. Souissi, N. Jemmali, H.K. Chakroun, J. Afr. Earth Sci. 110, 150 (2015)

4. R.C. Borges, V.G. Caldas, F.F.L.S. Filho, M.M. Ferreira, C.M.F. Lapa, Mar. Pollut. Bull. 89,75 (2014)

5. Y.X. Wang, Z.H. Bai, Acta. Mineral. Sin. 23, 51 (2003)

6. F.J. Zhang, Doctoral thesis, Dalian University of Technology, Dalian , 2013

7. Z.Y. Li, F. Wu, R.X. Hao, Acta Petrol. Mineral. 32, $1013(2013)$

8. W. Guo, R.X. Zhao, J. Zhang, Y. Y. Bao, H. Wang, M. Yang, X.L. Sun, F. Jin, Environ. Sci. 32, 3099 (2011).

9. E. Olkowska, B. Kudłak, S. Tsakovski, M. Ruman, V. Simeonov, Z. Polkowska, Sci. Total Environ. 476-477, 477 (2014)

10. E.G. Farmaki, N.S. Thomaidis, V. Simeonov, C.E. Efstathiou, Comparative Use of Artificial Neural Networks for the Quality Assessment of the Water Reservoirs of Athens, J. Water Supply Res. T. 62, 296 (2013)

11. F. Huang, X.Q. Wang, L.P. Lou, Z.Q. Zhou, J.P. Wu, Water Res. 44, 1562 (2010)

12. D.M. Han, J.P. Cheng, X.F. Hu, Z.Y. Jiang, L. Mo, H. Xu, Y.N. Ma, X.J. Chen, H. L. Wang, Mar. Pollut. Bul. 115, 141 (2017)

13. X. Li, H. Yang, C. Zhang, G.M. Zeng, Y.G. Liu, W. H. Xu, Y. Wu, S.M. Lan, Chemosphere 170, 17 (2017)

14. Q. Ding, G. Cheng, Y. Wang, D.F. Zhuang, Sci. Total Environ. 578, 577 (2017)

15. M. D'Emilio, M. Macchiato, M. Ragosta, T. Simoniello, J. Hazard. Mater. 241-242, 118 (2012)

16. Y.Y. Chen, Y.L. Liu, Y.F. Liu, A.W. Lin, X.S. Kong, D.F. Liu, X.R. Li, Y. Zhang, Y. Gao, D. Wang, Int. J. Env. Res. Pub. He. 9, 1874 (2012) 